\title{
Design gráfico e arte urbana como ferramentas para o desenvolvimento social*
}

\author{
Graphic design and urban art as tools for social development
}

\section{Design graphique et art urbain comme outils pour le développement social}

Diseño gráfico y arte urbano como instrumentos para el desarrollo social

\author{
Vivian Suarez Martins** \\ Gisela Belluzzo de Campos**
}

Recebido em 05/04/2016; revisado e aprovado em 04/08/2016; aceito em 27/09/2016

DOI: http:/ / dx.doi.org/10.20435/1984-042X-2016-v.17-n.4(07)

\begin{abstract}
Resumo: Este artigo discorre sobre as relações entre design gráfico socialmente orientado e intervenções urbanas na cidade de São Paulo. Entre trabalhos de artistas, designers e grafiteiros locais, destaca-se o projeto criado em 2011 por Thiago "Mundano" - o Pimp my Carroça, cujo objetivo é melhorar a vida dos catadores de lixo. $\mathrm{O}$ artigo descreve as ações desenvolvidas durante o evento, relacionado ao projeto, realizado em 2014.

Palavras-chave: design gráfico socialmente orientado; catadores de lixo; Pimp my Carroça.

Abstract: This article discusses the relationship between socially oriented graphic design and urban interventions in the city of São Paulo. Among the works done by artists, designers and graffiti artists operating in the city, highlight the project created in 2011 by Thiago "Mundano" - Pimp my Carroça, wich aims to improve the lives of the waste pickers. The article describes the actions taken during the event, related to the project, carried out in 2014.
\end{abstract}

Key words: socially oriented graphic design; waste pickers; Pimp my Carroça.

Résumé: Cet article traite de la relation entre le design graphique socialement orienté et les interventions urbaines dans la ville de São Paulo. Parmi les œuvres d'artistes, designers et grafitteurs locaux se démarque le projet créé en 2011 par Thiago «Mundane» - le Pimp My Carroça, qui vise à améliorer la vie des ramasseurs des déchets. L'article décrit les mesures prises lors de l'événement, liés au projet, réalisé en 2014.

Mots-clés: design graphique socialement orientée; ramasseurs des déchets; Pimp My Carroça.

Resumen: Este artículo se ocupa de la relación entre el diseño gráfico de orientación social y las intervenciones urbanas en la ciudad de Sao Paulo. Entre las obras de artistas, diseñadores y artistas de graffiti locales destaca el proyecto creado en 2011 por Thiago "Mundano" - el Pimp my Carroça, cuyo objetivo es mejorar la vida de los recolectores de basura. El articulo describe las acciones tomadas durante el evento relacionado con el proyecto, llevado a cabo en 2014.

Palabras clave: diseño gráfico de orientación social; recolectores de basura; Pimp my Carroça.

\section{INTRODUÇÃO}

O Pimp my Carroça é um programa que utiliza a arte como instrumento de conscientização, engajamento e transformação social e objetiva conquistar a inclusão social para catadores de materiais recicláveis, carroceiros e seus familiares, bem como vislumbrar melhores condições de trabalho. Com o objetivo de melhorar a vida desses trabalhadores e alertar a sociedade sobre a importância destes para o funcionamento das cidades, o grafiteiro Mundano criou o projeto cujo nome é uma paródia dos programas de TV que "tunam", reformam carros. O projeto

\footnotetext{
* O presente artigo é parte da Dissertação de Mestrado da primeira autora, sob orientação da segunda autora, intitulada "Expressões visuais e intervenções urbanas: design gráfico, ativismo e manifestação social", defendida no Programa de Pós-graduação Strito Sensu em Design na Universidade Anhembi Morumbi. A pesquisa de mestrado foi realizada com auxílio da Bolsa Capes.

** Universidade Anhembi Morumbi, São Paulo, São Paulo, Brasil.
} 
consiste basicamente em pintar os veículos de carroceiros da cidade de São Paulo com dois intuitos principais mais imediatos: dar visibilidade a estes trabalhadores informais no trânsito caótico da cidade, por onde as carroças circulam em meio a veículos motorizados leves e pesados, e conscientizar a população da importância de respeitar esse tipo de trabalhador. Mundano entrou no universo dos catadores e, desde a criação do Pimp my Carroça, não parou mais de trabalhar. O interventor afirma ter pintado mais de 200 carroças em várias cidades brasileiras, e já foi convidado a fazer exposições e viagens pelo mundo. Segundo Mundano, a "invisibilidade" dos catadores não é exclusividade do Brasil. "Eu os encontrei na Argentina, no Chile, Bolívia, África do Sul, Turquia e até mesmo em países desenvolvidos como Estados Unidos e Japão", afirma o ativista.

Até então atuando como grafiteiro, Mundano transferiu seu trabalho dos muros para as carroças, em 2007, entendendo esse veículo como um novo suporte para sua arte e mensagens que ambicionam atrair o olhar da sociedade para as disparidades e contradições sociais e chamar para a participação de cada um para a solução dos problemas coletivos. Desde as primeiras intervenções, Mundano constatou que a pintura de ilustrações de impacto e das frases de efeito nas carroças ampliava a interação das pessoas com os carroceiros, donos das carroças "pimpadas", que passaram a ser tratados com menos preconceito. O grafiteiro também percebeu que a carroça reformada, pintada e colorida, deixava o trabalhador mais feliz e com um perceptível fortalecimento da autoestima. Para Mundano, a invisibilidade dos catadores é o maior dos problemas enfrentados diariamente pelos catadores de recicláveis; sua ocupação é reflexo da desigualdade social, do desemprego e da abundância de resíduos sólidos, da deficiência do sistema de coleta.

Apesar de serem trabalhadores essenciais a toda a população, eles não são reconhecidos pela sua força de trabalho. Segundo o artista, eles coletam $90 \%$ de todos os resíduos que são reciclados no país, e a maioria trabalha de forma independente, apanhando resíduos das ruas e vendendo para o "ferro-velho" ${ }^{1 \text { " a preços }}$ muito baixos. Eles chegam a recolher mais de 300 quilos em suas bolsas, carrinhos, bicicletas e carroças, que são feitas de madeira ou metal e são encontradas em muitas ruas no Brasil.

Neste artigo, foi focalizado mais atentamente o Evento realizado em 2014, com duração de um dia - com início às $8 \mathrm{~h}$ e término às $18 \mathrm{~h}$, em um estacionamento aberto, no qual catadores, seus familiares e cães, que normalmente os acompanham nas ruas, receberam auxílio de artistas e profissionais da saúde e da higiene tais como dentistas, veterinários e pedicuros, para pintar as carroças, tratar os dentes, cuidar do pés, receber massagens e avaliar a saúde dos cães, entre outras ações visando ao bem-estar dos carroceiros e seus acompanhantes. Detivemo-nos sobre o modo como são aplicados elementos da linguagem gráfica na identidade visual do projeto, a fim de que as mensagens elaboradas nas peças, tais como material de sinalização e carroças propriamente ditas, venham a atingir os objetivos propostos, que são provocar e estimular reflexões ou ações no observador.

Foram criadas diversas peças gráficas dentre as quais se destacam aquelas destinadas à identificação dos veículos que consistem em pinturas com mensagens escritas - uma espécie de "cartaz" customizado para cada catador; os crachás de identificação para catadores, acompanhantes, equipe de trabalho, carroças; faixas de sinalização para as tendas de atendimento, entre outros.

O investimento em design gráfico e o cuidado com a linguagem visual auxiliam

\footnotetext{
1 Ferro-velho é o estabelecimento onde sucata é negociada; normalmente, os artigos de ferro usados são destinados à reciclagem por fundição.
} 
a validar a ação e torná-la mais atraente para os catadores, que percebem uma melhor aceitação da sociedade e um consequente fortalecimento na autoestima. Mundano afirma que, devido às carroças apadrinhadas por interventores, eles estão conseguindo vencer o preconceito, incrementar suas rendas e interagir de forma mais positiva com a sociedade.

\section{PROCEDIMENTOS METODOLÓGICOS}

O tipo de pesquisa que embasa este artigo é o estudo de caso e, para a sua construção, foram realizados os procedimentos descritos a seguir. A primeira fase consistiu em delimitar a unidade que constituiu o caso, a Edição 2014/SP do Evento Pimp My Carroça, o que demandou competência dos pesquisadores para perceber quais dados eram suficientes para se chegar à compreensão do objeto do estudo de forma ampla. Como nem sempre os casos são escolhidos de acordo com requisitos estatísticos, algumas coordenadas foram seguidas: a busca de um caso típico (em função da pesquisa prévia demonstrar ser o tipo ideal de estudo, aderente à investigação); a coleta de dados que foi a etapa seguinte, feita por procedimentos quantitativos e qualitativos: observação in loco, entrevistas formais (responsável pelo Pimp My Carroça) e informais (carroceiros), levantamentos de dados e análise de conteúdo. A terceira etapa foi constituída pela seleção, análise e interpretação dos dados coletados. A quarta e última parte foi a elaboração das considerações finais. Com o objetivo de caracterizar a relação do design gráfico com o evento analisado, foi realizada uma entrevista com os organizadores do Pimp my Carroça SP, representados pela colaboradora Bruna Menezes $^{2}$. A análise a seguir foi feita com base na visita ao evento e nas respostas dadas pela representante do grupo.

2 Entrevista concedida por Bruna Menezes a Vivian Suarez em janeiro de 2015, por email.

\section{IDENTIDADE VISUAL DO PROJETO}

A primeira impressão, após a visita e a leitura das respostas dadas às questões da entrevista, foi a existência da preocupação com o fortalecimento da identidade. O conjunto de elementos que estabelece a identidade visual e representa visualmente um projeto, produto, serviço ou evento em defesa de uma causa social, como o Pimp my Carroça, costuma ter como base o logotipo, um símbolo visual que se complementa nos códigos de cores, das tipografias, nos grafismos, em mascotes, personagens, nas personalidades e outros elementos que fortalecem o conceito a ser comunicado através dessa imagem. Um logotipo capaz de representar uma causa social (dentre outros segmentos) deve ser protegido por meio da criação e da consulta obrigatória de um manual da identidade visual. O Pimp my Carroça não conta com esse material, apesar de sua necessidade; tal documento ajudaria o evento a estabelecer normas e critérios técnicos de reprodução da marca em outras versões, em São Paulo ou fora do estado e país, nos mais variados suportes existentes, gráficos (impressão offset, serigrafia, etc) e eletrônicos (interfaces de websites e redes sociais).

Nesse sentido, foi constatado que existe uma série de elementos que caracterizam a presença do design gráfico na elaboração do evento, como logotipo (Figura 1), materiais de divulgação, entre outros, mas o projeto ainda carece do acompanhamento de um profissional ou agência de Design Gráfico que agregue ao projeto o valor necessário em termos de identidade visual. O logotipo foi criado por um designer gráfico, colaborador da equipe do projeto, e teve como inspiração a foto de um catador de recicláveis, cuja carroça havia sido personalizada por Mundano, criador do Pimp my Carroça; o logotipo agrega elementos que refletem a narrativa presente em todo o projeto: fontes 
tipográficas, pingos de tintas e máscaras de estêncil, que remetem à linguagem gráfica da arte urbana, das ruas; o símbolo da reciclagem e o verde utilizados ajudam a contextualizar o logotipo, conferindo-lhe um caráter ativista. Houve o desdobramento do logotipo do projeto e sua aplicação em diversas peças gráficas, colocadas à venda para captação de recursos (Figura 2) para a realização de outras versões do evento; camisetas, canecas, adesivos, gravuras e amassadores de latinhas são vendidos pelo site, por meio de solicitação por email.

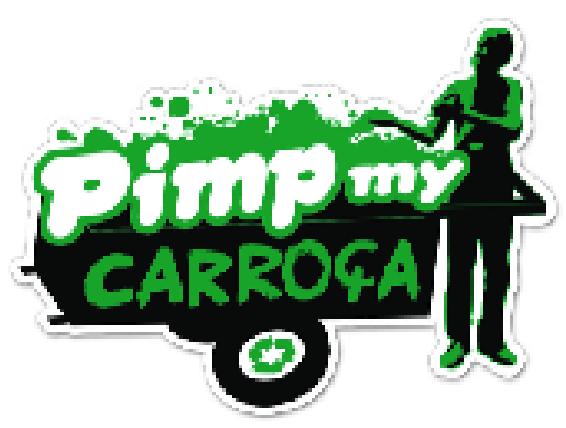

Figura 1 - Logotipo do projeto

Fonte: <pimpmycarroca.com>
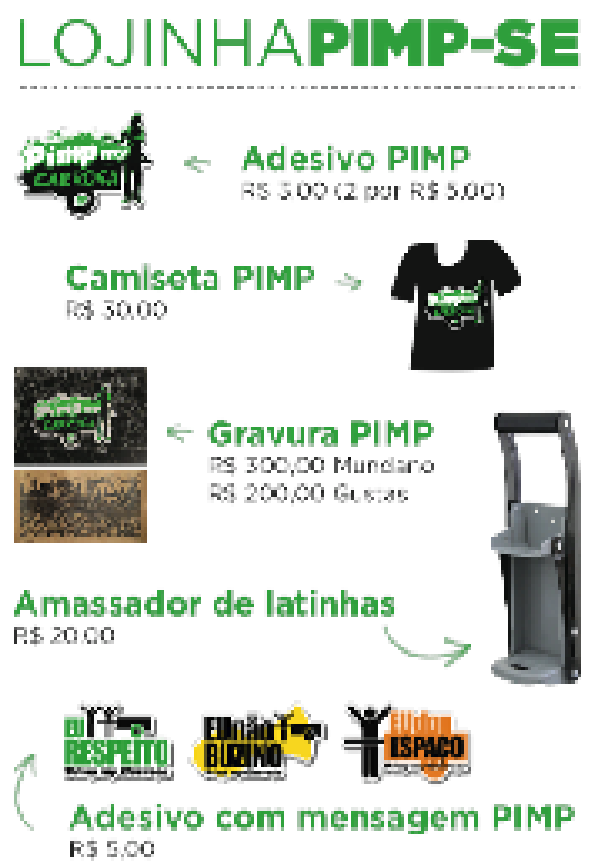

Figura 2 - Produtos à venda

Fonte: <pimpmycarroca.com>

O kit (Figura 3) entregue ao catador participante do evento era composto por buzina, espelho retrovisor, balança portátil, fitas refletivas, corda, sacos de ráfia, canetas Posca ${ }^{\circledR}$, óculos escuros Absurda ${ }^{\circledR}$, óculos de grau, luvas emborrachadas, adesivos, caneca, capa de chuva durável, calça com faixa refletiva, camiseta do evento com faixa refletiva para o catador, camiseta do Pimp para o voluntário, cartilhas, dentre outras surpresas. A maioria dos componentes do kit tem o logotipo do Pimp my Carroça, e isso faz com que a identidade da marca seja fortalecida, pois os catadores ajudam a propagar uma mensagem e a divulgar o projeto.

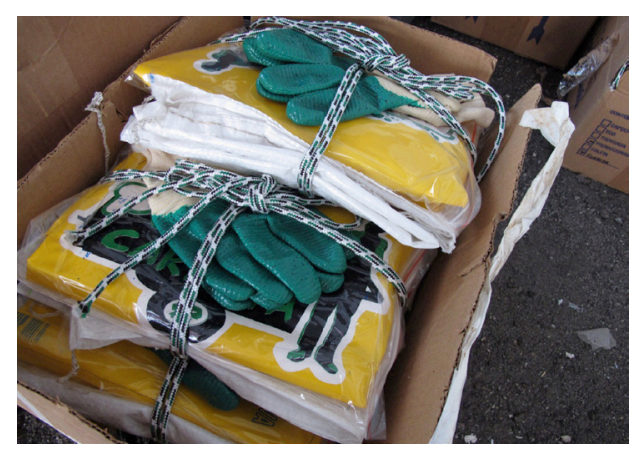

Figura 3 - Kit do Catador, distribuído na edição de 2014

Fonte: Arquivo pessoal das autoras.

\section{DESIGN GRÁFICO NO EVENTO}

Durante a realização do evento, ficou bastante clara a presença do design gráfico como forte ferramenta para o estabelecimento da comunicação entre os organizadores e os catadores, bem como seus acompanhantes e familiares. As carroças que estavam sendo "pintadas" durante o evento eram identificadas por meio de crachá, com campos que permitiam o acompanhamento do status da reforma; na chegada do catador, as carroças eram fotografadas para possibilitar a comparação do "antes e o depois" da restauração. Além das carroças e catadores, todos os envolvidos com o evento eram identificados com seus respectivos crachás: equipe (colaboradores e voluntários), catadores e acompanhantes (familiares e animais) (Figura 4). Os 
acompanhantes identificados tinham acesso a todas as tendas do evento; massagem, podologia, odontologia, atendimento médico, oftalmologia (com exame de visão), estética, (maquiagem e corte de cabelo), além de receberem um vale-alimentação para terem acesso ao almoço, servido em um restaurante conveniado, próximo ao local do evento. Os animais, numerosos, eram identificados e atendidos na tenda dos veterinários. Além da identificação dos participantes e suas carroças, a sinalização das tendas foi uma preocupação dos organizadores, que utilizaram uma linguagem das ruas, da arte urbana para demarcar todos os espaços e, assim, facilitar o trânsito para os participantes; trocadilhos verbais e visuais foram criados para nomear as barracas e dar ao evento a leveza necessária para receber os catadores (Figura 5); a estratégia dos organizadores, com a utilização da linguagem e elementos verbais e visuais escolhidos, era a de envolver os participantes numa atmosfera de harmonia, e, assim, afastá-los, ainda que temporariamente, da dura realidade do seu cotidiano. O título da tenda de "martelinho de ouro", faz menção ao serviço feito, geralmente, em carrocerias de veículos, mas, no evento, serviu como analogia à massagem realizada nos catadores e seus familiares. Todas as tendas foram sinalizadas, e o humor foi uma marca característica de todos os títulos.

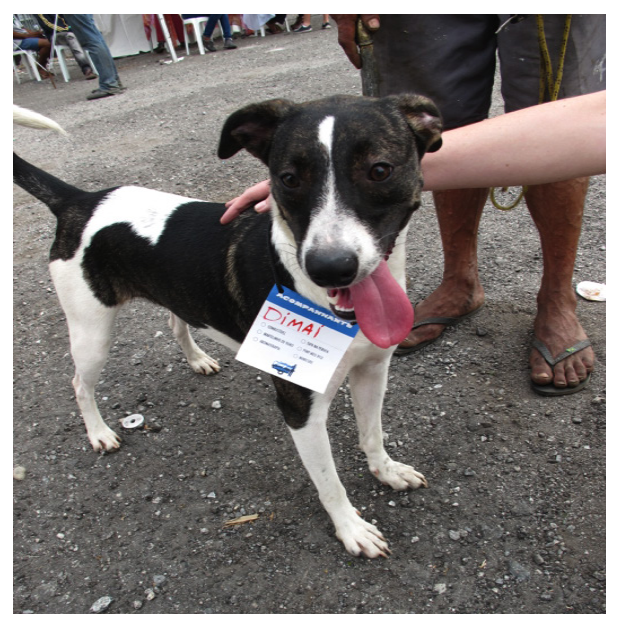

Figura 4 - Dimai: cão identificado e atendido durante o evento

Fonte: Arquivo pessoal das autoras.

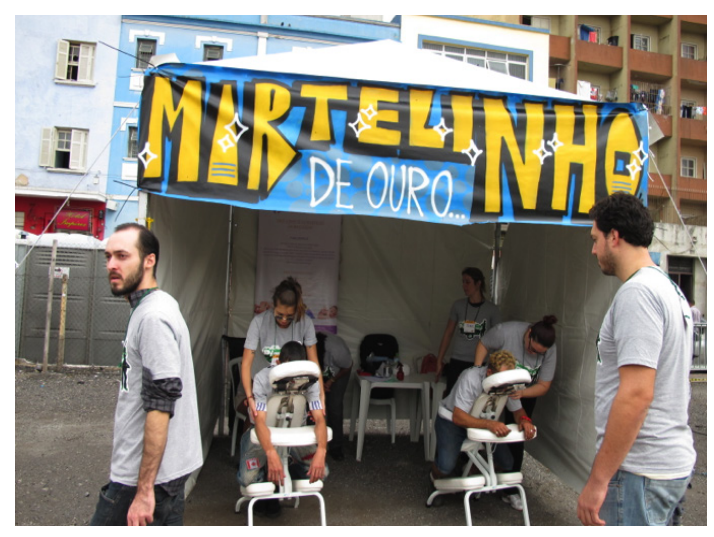

Figura 5 - Sinalização em tenda de massagem

Fonte: arquivo pessoal das autoras

Os participantes, além de identificados por crachá, recebiam a camiseta do evento, em duas versões: catadores e equipe (voluntários); a frase "catador com muito orgulho", estampada no verso das camisetas distribuídas aos beneficiados, refletia o sentimento, generalizado entre os catadores. Com uma letra de fácil leitura, impressa em serigrafia e monocromia (tinta preta), a frase contrastava com a cor cinza de fundo das camisetas. O logotipo do Pimp my Carroça, estave presente em diversas peças gráficas, evidenciando a presença do Design gráfico em todo o evento; adesivos com mensagens de apoio foram distribuídos gratuitamente; trata-se de uma forma eficaz de propagar a mensagem onde o desrespeito ao catador é mais recorrente: no trânsito de carros da cidade.

A preocupação em divulgar o projeto, também nas redes sociais, era evidente, pois o \#pimpmycarroca estava estampado em diversos locais do espaço; ao fotografar com seus smartphones durante o evento, os participantes eram estimulados a postar suas imagens no suporte web, em aplicativos de redes sociais, identificando as imagens com a utilização da hashtag do evento. 


\section{CUSTOMIZAÇÃO DAS CARROÇAS}

Uma característica marcante do evento e da participação dos artistas interventores foi a heterogeneidade de perfis, estilos e técnicas utilizadas na pintura das carroças; os artistas "pimpadores", como são chamados durante o evento, utilizam as carroças como um suporte diferenciado para suas obras de protestos, que têm como objetivo esclarecer as contradições sociais e despertar o papel individual de cada um para a resolução dos problemas coletivos. Nesse sentido, muitos interventores utilizaram, em paralelo às suas habituais técnicas de intervenção, frases de efeito nas carroças; com isso, buscaram estimular a interação das pessoas com os catadores, para lutar contra o preconceito e elevar sua autoestima. A figura 6, mostra um exemplo de carroça personalizada pelo interventor e criador do evento, Thiago Mundano. Com a frase "Não buzine, me dê bom dia!, o interventor pretendeu levar os motoristas, personagens do trânsito de São Paulo, à reflexão e consequentemente à valorização e ao respeito ao catador de material reciclável e sua ferramenta de trabalho, a carroça de coleta. A técnica utilizada foi a do grafite à mão livre, com tinta em spray; o uso de letras grandes e cores contrastantes foi pensado para facilitar a leitura a distância.

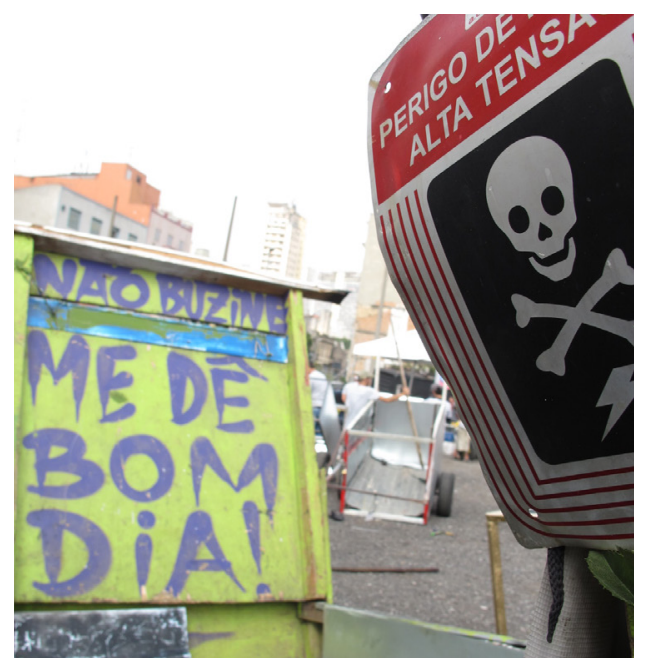

Figura 6 - Detalhe da carroça

Fonte: Arquivo pessoal das autoras
Centenas de latas de spray e caps (pontas de plástico utilizadas para lançar o jato do aerossol) foram distribuídos aos interventores convidados, além de pincéis, máscaras de estêncil e outros materiais necessários para a realização do trabalho. Os artistas puderam expor suas habilidades por meio da criação com ilustrações complexas, tipografias manuais elaboradas, aplicação de máscaras de estêncil minuciosamente criadas e refiladas, dentre outras técnicas; o marco comum a todos era a disponibilidade de colaborar de forma gratuita, além de imprimir mensagens de forte cunho social para que a mensagem, em favor dos catadores, fosse mais facilmente propagada, após a realização do evento e nas ruas de São Paulo. Na figura 7, o "pimpador" Shock Maravilha ilustra, com maestria, uma das peças no evento; utilizando a técnica do grafite, mão livre e latas de spray, criou uma composição em tons de verde e contorno em preto para personalizar a carroça.

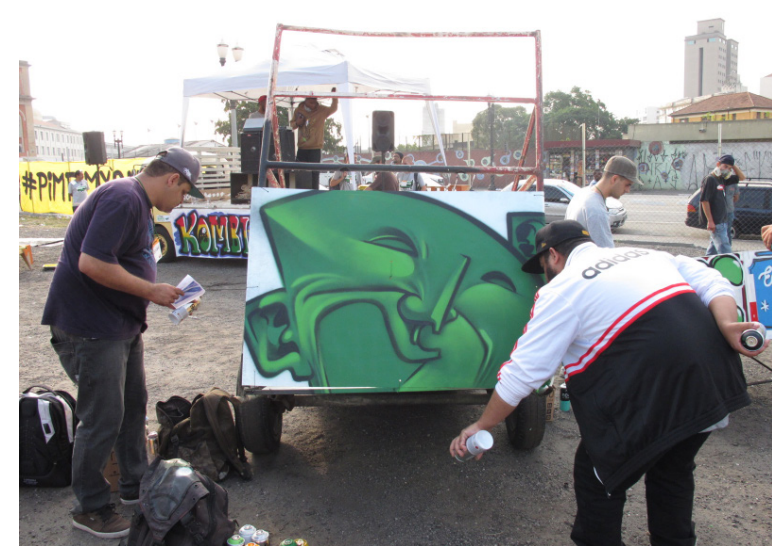

Figura 7 - Trabalho em andamento; ilustração de Shock Maravilha Fonte: Arquivo pessoal das autoras

A pintura com máscaras de estêncil foi bastante utilizada por grande parte dos interventores, isoladamente ou em conjunto com outras técnicas, como as criadas pela estencilista interventora Simone Siss Sapienza. O grafite esteve presente em grande parte das intervenções, impresso com a utilização de tintas 
em latas, spray, pincel ou rolinho. A figura 8, mostra o trabalho da interventora Erica Maradona, que trouxe a linguagem do cordel e fez forte referência a elementos nordestinos. A figura de um sertanejo foi pintada na carroceria, fortalecida pela frase "Ai que saudade eu tenho da Bahia, ai se eu escutasse o que mamãe dizia". Vale ressaltar que grande parte dos catadores de recicláveis, que atuam em São Paulo, vem das regiões Norte e Nordeste, e isso serviu de mote para a interventora e sua bela obra, delicadamente decorada com fitas de cetim coloridas.

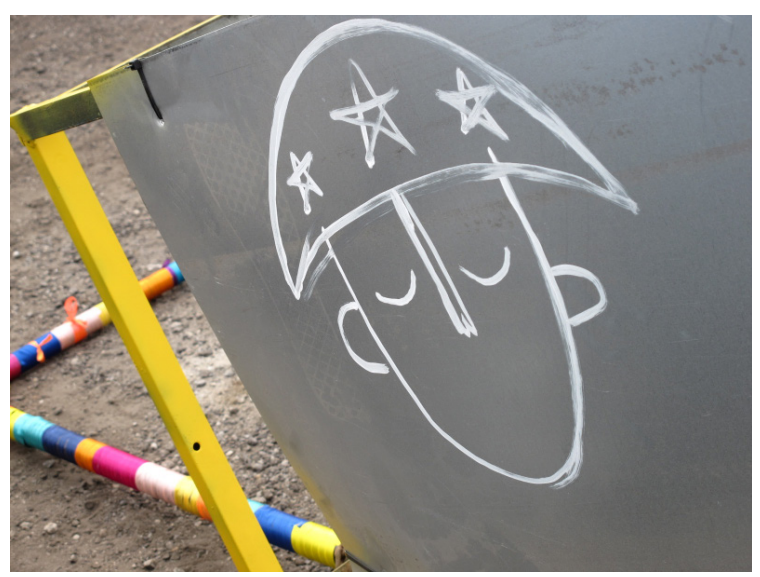

Figura 8 - Trabalho da interventora Erica Maradona

Fonte: Arquivo pessoal das autoras

Muitas foram as formas utilizadas na customização das carroças, tais como a máscara de estêncil sobre imagem já pintada. Algumas máscaras tinham recortes geométricos; outras, divididas em várias camadas, representavam a figura humana, como a da Figura 9, na qual cada cor foi impressa sobre uma máscara distinta de estêncil; a sobreposição das imagens deu origem à composição do rosto pintado.

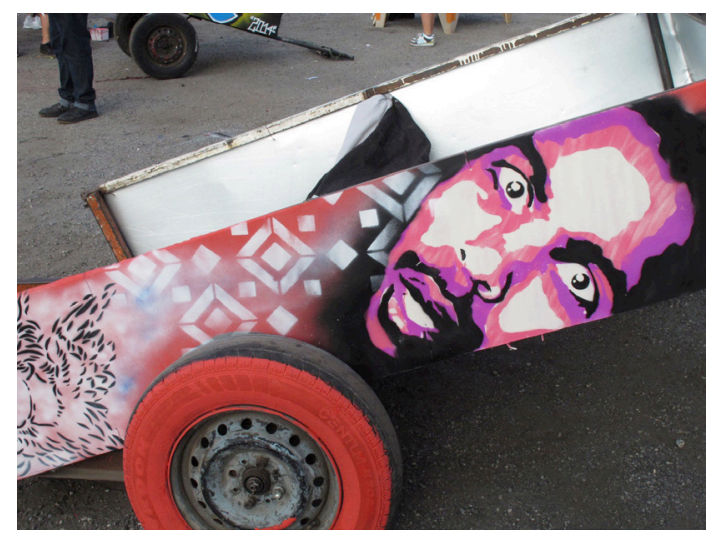

Figura 9 - Lateral da carroça customizada Fonte: Arquivo pessoal das autoras.

A tipografia teve presença marcante na customizacão das carroças. A figura 10 ilustra o trabalho elaborado do caligrafista Tipocali; com fontes manuscritas, em estilo próprio do interventor, uma carroça é inteiramente escrita e pintada com cores contrastantes, preto e branco. No início da mensagem, apesar do rebuscamento das fontes utilizadas, pode-se ler a frase "Seu Lixo, Seu luxo". Diversos estilos e técnicas ilustraram o evento, e cada interventor buscou levar sua personalidade às carroças "pimpadas".

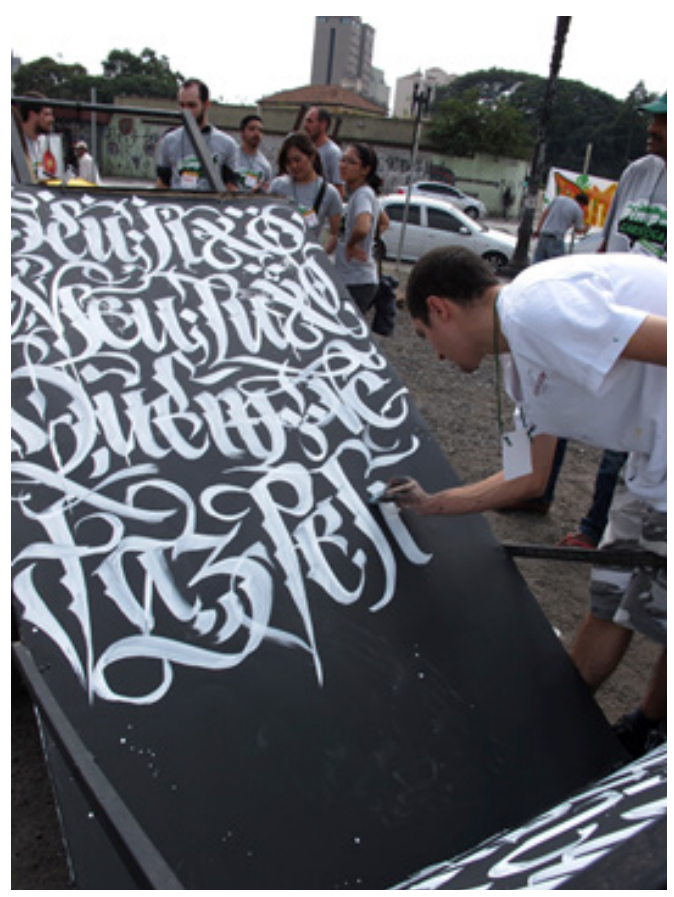

Figura 10 - Trabalho em andamento; mensagem sendo escrita pelo interventor Tipocali

Fonte: Arquivo pessoal das autoras. 


\section{CONSIDERAÇÕES FINAIS}

O presente artigo constituiu-se em uma discussão proposta sobre as articulações entre a linguagem gráfica e as intervenções no ambiente urbano e sobre a presença e a importância do design gráfico socialmente orientado. $\mathrm{O}$ design nasceu para criar e transmitir mensagens aos indivíduos, consumidores, eleitores, espectadores ou as pessoas que o designer pretenda atingir (BRAGA, 2011), e, no contexto deste artigo, o interventor gráfico foi colocado no mesmo papel, como o emissor de mensagens e o responsável por levar seu público à reflexão. No âmbito do design, na ponta da cadeia produtiva, está o consumidor que, como usuário de produtos ou serviços, pode ter participação ativa na busca de mudança social, do seu próprio contexto ou de outros indivíduos. A força motriz do design socialmente orientado e engajado está exatamente no poder de ação e transformação desse indivíduo consumidor; no que se refere à arte urbana, esse "consumidor" passa a ser um indivíduo que pode ou não ser influenciado pela obra à qual é apresentado, e, a depender do impacto, pode se tornar um propagador da mensagem transmitida pelo interventor e autor da peça gráfica.

Para Ledesma (1997) o design gráfico é uma forma de comunicação específica, mas essa especificidade ainda é indeterminada; sustentado pela tríade canal visual, meios e caráter massivo, o design gráfico é um tipo de comunicação que recorre ao visual e, através dos meios, estabelece uma distância maior ou menor entre emissor e receptor. Em concordância com a autora, concluímos que o design gráfico admite o desenvolvimento e circulação de peças e mensagens em distintos meios: jornais, livros, ruas, televisão, internet etc., e, com âmbito comunicacional claro, o de tradição urbana, circula em todas as partes, mas remete à cidade, cujo caráter de comunicação é coletivo e social.
No caso do estudo apresentado, ficou clara a participação do design gráfico, ainda que, de maneira relativamente amadora, e da linguagem visual como agentes propulsores da modificação social, principal objetivo almejado pelos organizadores do Pimp my Carroça; o fortalecimento da autoestima dos catadores e o seu consequente empoderamento e mudança de percepção do contexto onde vivem foram viabilizados, também, pela utilização dos elementos da linguagem visual nas obras realizadas, tendo como suportes as carroças, além de todo o material gráfico criado especificamente para o evento realizado em 2014.

O design gráfico socialmente orientado se aproxima da arte urbana ativista no que se refere à busca pela atenção de indivíduos e pelo seu consequente despertar para a reflexão e tomada de decisões em prol de um grupo, do coletivo. A ação positiva e a propagação da mensagem socialmente orientada é um resultado esperado dessa reflexão.

Design gráfico é um dos mecanismos disponíveis para a cultura processar e comunicar informações. Sabe-se que diversas construções culturais podem cumprir essa função, mas, para Ledesma (1997) - e para as autoras deste artigo a especificidade do design gráfico está no tipo de informação. O design gráfico organiza informações legíveis e visíveis e, com isso, pode regular comportamentos. Trata-se, então, de um processo de coesão cultural que, em qualquer de suas manifestações, opera em toda a sociedade e, em outros, determinados e específicos setores sociais, como ocorreu no Pimp my Carroça 2014. Nesse evento específico, o design gráfico, ainda que fora de um contexto profissional e comercial, definiu uma estrutura, criou um sistema de significados, gerou códigos específicos e, finalmente, produziu efeitos de percepção, recepção e comportamentos.

Em suma, este artigo procurou caracterizar a participação do design gráfico 
socialmente orientado como agente de modificação social, almejada por interventores urbanos contemporâneos na criação e divulgação de suas peças gráficas.

\section{REFERÊNCIAS}

BRAGA, Marcos da Costa (Org.). O papel social do design gráfico. 1. ed. São Paulo: SENAC-SP, 2011.

LEDESMA, María. Diseño gráfico, un ordem necessário? In: ARFUCH, L.; CHAVES, N.; LEDESMA, M. Diseño y comunicación. Teorías y enfoques críticos. Buenos Aires: Paidós, 1997.

\section{Sobre as autoras:}

Vivian Suarez Martins: Doutoranda e Mestre em Design pela Universidade Anhembi Morumbi. E-mail: contato@vickasuarez.com

Gisela Belluzzo de Campos: Professora e pesquisadora do Programa de Pósgraduação Stricto Sensu em Design na Universidade Anhembi Morumbi. Desenvolve pesquisa em design gráfico contemporâneo em diferentes meios e suportes. E-mail: giselabelluzzo@uol.com.br 
